\title{
Analysis of the carbon metabolism of Rhodopseudomonas palustris for biohydrogen production
}

\author{
Ezgi Melis Doğan-Güner ${ }^{(}$, Harun Koku*
}

Department of Chemical Engineering, Faculty of Engineering, Middle East Technical University, Dumlupınar Bulv. No. 1, 06800 Ankara, Turkey.

\section{How to cite}

Doğan-Güner, E. M., \& Koku, H. (2022). Analysis of the carbon metabolism of Rhodopseudomonas palustris for biohydrogen production. Biotech studies, 31(1), 1-9. https://doi.org/10.38042/biotechstudies.1062792

\section{Article History}

Received 24 August 2021

Accepted 15 December 2021

First Online 10 January 2022

\section{Corresponding Author}

Tel.: +90 3122102610

E-mail: harunk@metu.edu.tr

\section{Keywords}

R. palustris

Flux balance

Hydrogen production

Sucrose

\begin{abstract}
Hydrogen can be produced renewably and sustainably by the purple non-sulfur bacterium Rhodopseudomonas palustris from sucrose. To improve hydrogen production, detailed insight is needed, which can be obtained by studying the coupling of carbon fluxes with the light utilization apparatus and the hydrogen producing enzymes. In this study, the flux balance analysis approach was used to construct a model of the central carbon metabolism of this organism and solve the resulting network for a chosen objective function. The model was able to closely reproduce key qualitative and quantitative aspects of an independent experimental study. Further insight was obtained by additional case studies. Specifically, it was found that extreme light intensities resulted in the decrease of hydrogen production, that hydrogen production could be possible even when no light is provided, and a mix of sucrose and an organic acid could improve hydrogen production, which can be explained and supported by prior work on this organism. Further investigation is necessary to investigate the connections between metabolic network components, such the antagonistic relationship between hydrogen and polyhydroxybutyrate, which is a reserve product of this microorganism.
\end{abstract}

\section{Introduction}

Energy consumption worldwide has been rising and depends mostly on non-renewable fossil fuels. Hydrogen $\left(\mathrm{H}_{2}\right)$ is one of the prospective replacement alternatives for fossil fuels (Das \& Veziroglu, 2001). It has a high per-mass energy content $(122 \mathrm{~kJ} / \mathrm{g})$ and evolves only water in combustion, suggesting a clean, sustainable and environmentally friendly fuel for energy demand in the future (Argun et al., 2008; Kotay et al., 2008). However, in order for hydrogen to become a viable option, it has to be produced renewably.

Biological hydrogen production from microorganisms has the advantages of renewable substrates, low energy consumption and mild operating conditions (Azwar et al., 2013). Several families of microorganisms, such as the photosynthetic purple non- sulfur bacteria (PNSB), algae and cyanobacteria, produce hydrogen (Sparling et al., 2012). PNSB are promising candidates for biological hydrogen production (Basak et al., 2007) as they accomplish lightdriven conversion of organic compounds to hydrogen with high efficiency and are metabolically versatile, which enables them to use a large variety of simple and complex feedstock including food and agricultural wastes. PNSB include species such as Rhodobacter capsulatus, Rhodobacter sulfidophilus, Rhodobacter sphaeroides, Rhodopseudomonas palustris and Rhodospirillum rubrum, all capable of producing hydrogen using energy from light and a source of organic carbon, such as sugars and short chain organic acids, which can be found in agricultural and industrial wastes (Eroglu et al., 2014). 
Despite their versatility, enhancing the hydrogen productivities (rate per volume of culture) from PNSB remains a challenge due to their complex metabolism. Hence, a thorough understanding of the metabolism of these species plays a vital role in assessing this challenge and identifying the prospects for metabolic engineering to improve productivity. The present study is an analysis of the hydrogen-production metabolism of PNSB, using metabolic analysis.

In PNSB, hydrogen is produced via a light-driven metabolism utilizing the hydrogen-producing enzymes hydrogenase and nitrogenase in the absence of oxygen (Vignais et al., 1985). The overall hydrogen metabolism results from the interaction of several components along with the enzymes, as summarized in Figure 1, adapted from the study of Koku et al. (2002). Sucrose is assimilated by the sucrose pathway, glycolysis and the TCA cycle. The electrons that are extracted from the substrate are transferred to the electron carriers NAD (Nicotinamide adenine dinucleotide) and $\mathrm{Fd}$ (Ferredoxin) and in turn utilized by nitrogenase and hydrogenase in addition to other pathway blocks such as the Calvin cycle. Light is converted in the Photosynthetic unit (PSU) to ATP, which in turn is directed to nitrogenase along with the protons and electrons. Protons are supplied by the TCA cycle and ATP-synthase, the latter a part of the photosynthetic apparatus. Over-reduction due to excess electrons in the system is the main cause of hydrogen production (McEwan, 1994). Various strategies have been previously implemented, based on targeting of the primary systems of Figure 1, such as the overexpression of genes, elimination of competitive pathways and implementation of new hydrogen production pathways and engineering the genes of nitrogenase and hydrogenase (Ozturk et al., 2006). Oh et al. (2011) have summarized various metabolic engineering studies on PNSB for improved bio-hydrogen production.

While an overall schematic is conceptually useful, for a more thorough understanding of hydrogen metabolism, genome-based metabolic models are necessary (Hallenbeck \& Liu, 2016). Metabolic flux analysis is such a computation-assisted method for this purpose. In this method, a single cell is treated as a system that exchanges mass with its surroundings, as well as carrying out internal (intracellular) reactions. The magnitudes of the calculated rates of the reactions, called fluxes are calculated by linear programming techniques and reveal detailed information on resource utilization and product turnover. The model, and the procedure employed in this study can thus provide insight into biological hydrogen production.

Several prior studies have investigated the metabolism of PNSB, with various goals and model sophistication. Klamt et al. (2002) identified metabolic constraints via a metabolic flux analysis applied to the central photogermentative metabolism of PNSB. Golomysova et al. (2010) applied FBA to the first comprehensive model of PNSB metabolism using $R$. sphaeroides where 314 metabolic reactions were accounted for, with 287 compounds involved. The computed metabolic fluxes were compared with those in previous experimental studies. Similarly, Imam et al. (2011) used a model with 796 metabolites and 1158 reactions of $R$. sphaeroides. Their results were close to experimental observations and the authors pointed out competing pathways as a cause of low yields of $\mathrm{H}_{2}$ production. Navid et al. (2019) studied aspects of anaerobic photoheterotrophic growth of $R$. palustris on acetate with a genome-wide metabolic model and compared the allocation of resources for several cases.

The model species of the present study is $R$. palustris due to its good hydrogen yield on sucrose (Sagir et al., 2017, Zhang et al., 2015). Furthermore, the genome sequence of $R$. palustris has been published and available (Larimer et al., 2004). Based on this sequence it has been possible to distinguish several metabolic capabilities of $R$. palustris, not in common with other PNSB. For instance, $R$. palustris can harvest light of differing qualities and intensities. It carries out asymmetric cell division and secretes a surface adhesive allowing it to stick to solid substrates, an advantage for hydrogen production (Larimer et al., 2004). Sagir et al. (2017) experimentally observed $R$. palustris having the maximum hydrogen productivity $(0.78 \mathrm{mmol} / \mathrm{h})$ from

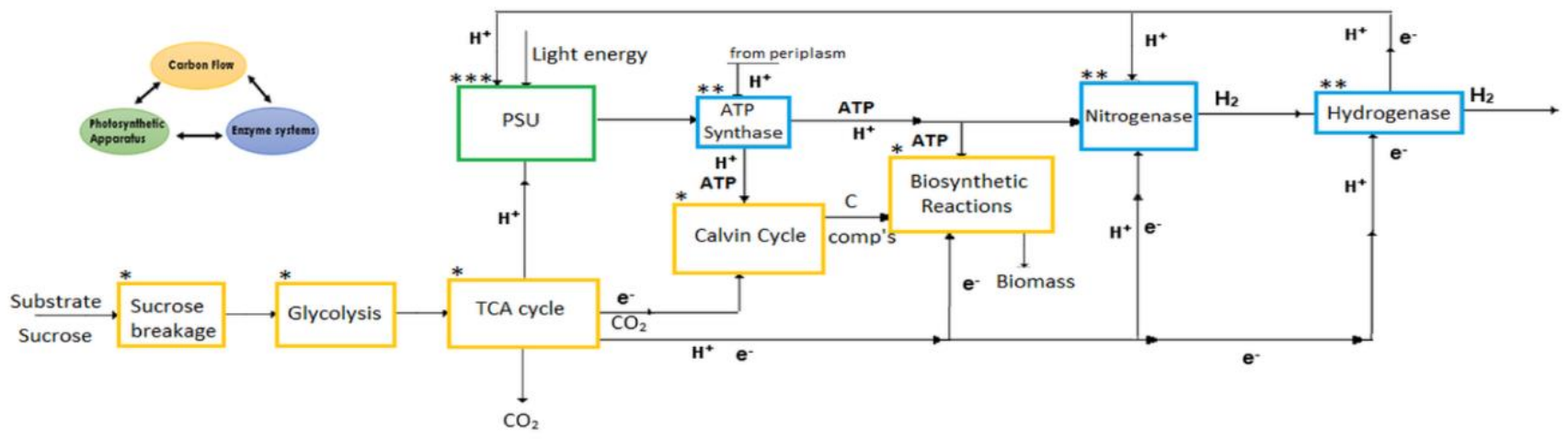

Figure 1. The overall scheme for hydrogen production.

Boxes: $\left({ }^{*}\right)$ Carbon flow, $\left({ }^{* *}\right)$ Enzyme systems, $\left({ }^{* *}\right)$ Photosynthetic unit (PSU) 
sucrose among the PNS species studied, namely $R$. capsulatus, $R$. capsulatus $\mathrm{YO} 3$ (hup-), and $R$. sphaeroides.

In the present study, the starting concentrations of the carbon source sucrose and the nitrogen source glutamate were chosen such that the carbon-tonitrogen ratio values were close to those typically used in experimental hydrogen production studies. Sucrose, the principal component of molasses, is a relatively cheap feedstock, thus resulting in a lower cost process for hydrogen production (Keskin et al., 2012).

\section{Materials and Methods}

\section{Flux balance analysis and underlying assumptions}

We used flux balance analysis (FBA), where bacterial metabolism is analogous to a set of biochemical reactions occurring in a reactor. Details of the algorithm are well-established (Stephanopoulos et al., 1998). A key assumption is the pseudo steady-state condition for cellular metabolism, leading to constant fluxes and a set of linear mass balance equations, and obviating the need for kinetic parameters. This set of equations can be presented in matrix form, with the $m$ $\times \mathrm{n}$ stoichiometric matrix $(\underline{\mathrm{S}})$ and the unknown $\mathrm{n} \times 1$ flux vector $(\underline{v})$, where $m$ is the number of metabolites and $n$ is the number of the reactions. Equation (1) displays the system of equations in compact form, with each row corresponding to the sum of the fluxes for a particular metabolite (equations) and each column to a particular flux.

$$
\underline{\underline{S}} \cdot \underline{v}=0(1)
$$

To consolidate the equation system, intermediate metabolites that are produced and consumed in irreversible reactions without branching are neglected (Varma \& Palsson, 1993), and compounds that are not key metabolites are excluded. Some biosynthetic reactions can be lumped into a single reaction when intermediates are not of interest. Furthermore, cofactor carrier species such as coenzyme $A$ and $N A D^{+}$have their fluxes intrinsically balanced and can therefore be ignored in the network. Inclusion of such metabolites only leads to the generation of dependent rows (Varma \& Palsson, 1994).

\section{Objective function and constraints}

Typically, as in this study, the number of equations is less than the number unknowns $(m<n)$. Thus an objective function is defined and mathematically optimized, with the known flux equations (i.e. the set formulated as equation 1) constraining the solution space. Subsequently a unique optimum solution and a corresponding optimal flux distribution for the metabolic network are obtained.

The objective function is usually set to maximize the growth rate of the biomass since this is arguably the natural goal of the cell (Varma \& Palsson, 1994). The case for other objective functions such as maximization of certain products, maximization of ATP production or minimization of substrate consumption, has been argued for and against, as discussed in (Feist et al., 2010). In the present study, most solutions were obtained for the default objective function of maximized growth, except for a few explicitly stated cases with maximum hydrogen production as the objective.

There are no well-defined rate limitations for a specific enzyme or a set of enzymes in the metabolic network of $R$. palustris, thus the flux vector values were allowed a large range of -1000 to +1000 , respectively to ensure convergence and obtain finite values. No solutions were found when unconstrained sets were used. Reversible reactions in the metabolic network can have positive or negative flux values, with the sign of the flux indicating the direction (Edwards et al., 2000). In the model of the present study, 50 out of 148 reactions are reversible and thus their resulting values can be positive or negative.

\section{Optimization}

The simplex method is most commonly used, but the interior-point method was preferred in this study. Trial solutions are corner-point feasible solutions in the simplex method, whereas in the interior-point algorithm they originate inside the feasible domain, which promotes a better chance of reaching a solution when corners or edges are not well-defined, or when the unknown vector contains negative values (Venkataraman, 2009).

\section{Modeling methodology}

The initial stage was the reconstruction of the cellular metabolism in terms of metabolic pathways and their reactions. Biochemical reactions were identified from databases to construct a general, overall metabolic network for PNS bacteria (R. palustris CG009) and listed in standard stoichiometric notation. Most reactions were obtained from the KEGG database (Kanehisa et al., 2015) whereas MetaCyc (Caspi et al., 2014) and BRENDA (Schomburg et al., 2013) databases were used to check enzymes/reactions not available in KEGG database.

In the preparation stage, the network was simplified for $R$. palustris and the conditions of interest. For each a reaction/enzyme among metabolic reactions, the databases as well as the literature data for this species were scanned. If the presence of this enzyme was confirmed either via the genomic map or the literature data, the selected reaction was included in the network. Pathways inactive under hydrogen-producing conditions were eliminated, for example, since anaerobic conditions are required for photofermentative hydrogen production, aerobic respiration were excluded.

In the development stage, the metabolic network was formulated with the selected reactions and the stoichiometric matrix was constructed. Stoichiometric reductions were carried out to form a fully independent 
linear system. An objective function and constraints were set up as described above.

In the calculation/result stage, first an optimization script was formulated using MATLAB R2016. The script was verified using by a prior test-case with known results (Varma et al., 1993b) and the resulting flux values were found to be almost identical.

After verification, the script was applied to the stoichiometric matrix for $R$. palustris. The final metabolic model consists of 148 reconstructed biochemical reactions with 128 compounds within the reaction network. Eliminating dependent reactions reduced the number of rows in the stoichiometric matrix from 128 to 121. Pseudo steady-state was assumed for the metabolic network and the objective function was assumed as either maximal growth of biomass or hydrogen production, as explained above.

\section{Results and Discussion}

\section{Metabolic network}

The reconstructed metabolic network consists of the core metabolic blocks necessary for growth and hydrogen production. These blocks include the sucrose assimilation pathway, the pentose phosphate pathway, glycolysis, Calvin cycle, TCA cycle, PHB synthesis, lumped biosynthetic (growth) reactions, photosynthetic reactions and hydrogen production reactions. Pathways in which maltose, pectin and cellulose are consumed, and the pathways that require aerobic respiration were not included. In the central metabolic network, sucrose was considered as the primary carbon source and glutamate the nitrogen source in a growth medium with low nitrogen to carbon ratio, to emulate typical conditions used for hydrogen production.

Figure 2 displays the reconstructed carbon flow network. Gray boxes contain biosynthetic precursors for biomass growth. Some metabolites reacting at separate regions of the network are color-coded to represent the network in two dimensions. Each major pathway block is letter-coded (A-F in Figure 2): Carbon utilization starts with external sucrose which is broken down in the sucrose pathway (A). Phosphorylated glucose enters glycolysis (B) and the pentose phosphate pathway (C), the latter being specific to $R$. palustris among the PNS bacteria. Following 3-Phospho-D-glycerate, carbons are utilized in the Calvin cycle (D). Organic acids are produced in TCA cycle (E). Fluxes 39 and 40 in the TCA Cycle are the glyoxylate shunt, which is specific to $R$. palustris among PNSB. ATP, $\mathrm{CO}_{2}$ and electrons are produced and consumed throughout these pathways while NAD and FAD shuttle electrons to the reactions. Residual electrons and ATP are consumed for hydrogen production by nitrogenase and hydrogenase. The production of PHB (F) is also accounted for in the model. The hydrogen production reactions are outside the scope of the central carbon network and summarized in Table 1.

Table 1. Reactions for hydrogen production with their resulting fluxes

\begin{tabular}{llc}
\hline \multicolumn{1}{c}{ Enzyme } & \multicolumn{1}{c}{ Reaction } & $\begin{array}{c}\text { Flux } \\
\text { (mmol/h) }\end{array}$ \\
\hline Mo-Nitrogenase & $-16 \mathrm{ATP}+8 \mathrm{H}^{+}+8 \mathrm{e}^{-} \rightarrow 16 \mathrm{ADP}+4 \mathrm{H}_{2}$ & 0.048 \\
V- Nitrogenase & $-16 \mathrm{ATP}+8 \mathrm{H}^{+}+8 \mathrm{e}^{-} \rightarrow 16 \mathrm{ADP}+4 \mathrm{H}_{2}$ & 0.048 \\
Fe- Nitrogenase & $-16 \mathrm{ATP}+8 \mathrm{H}^{+}+8 \mathrm{e}^{-} \rightarrow 16 \mathrm{ADP}+4 \mathrm{H}_{2}$ & 0.048 \\
Hydrogenase & $2 \mathrm{H}^{+}+2 \mathrm{e}^{-} \rightarrow \mathrm{H}_{2}$ & 0.11 \\
\hline
\end{tabular}

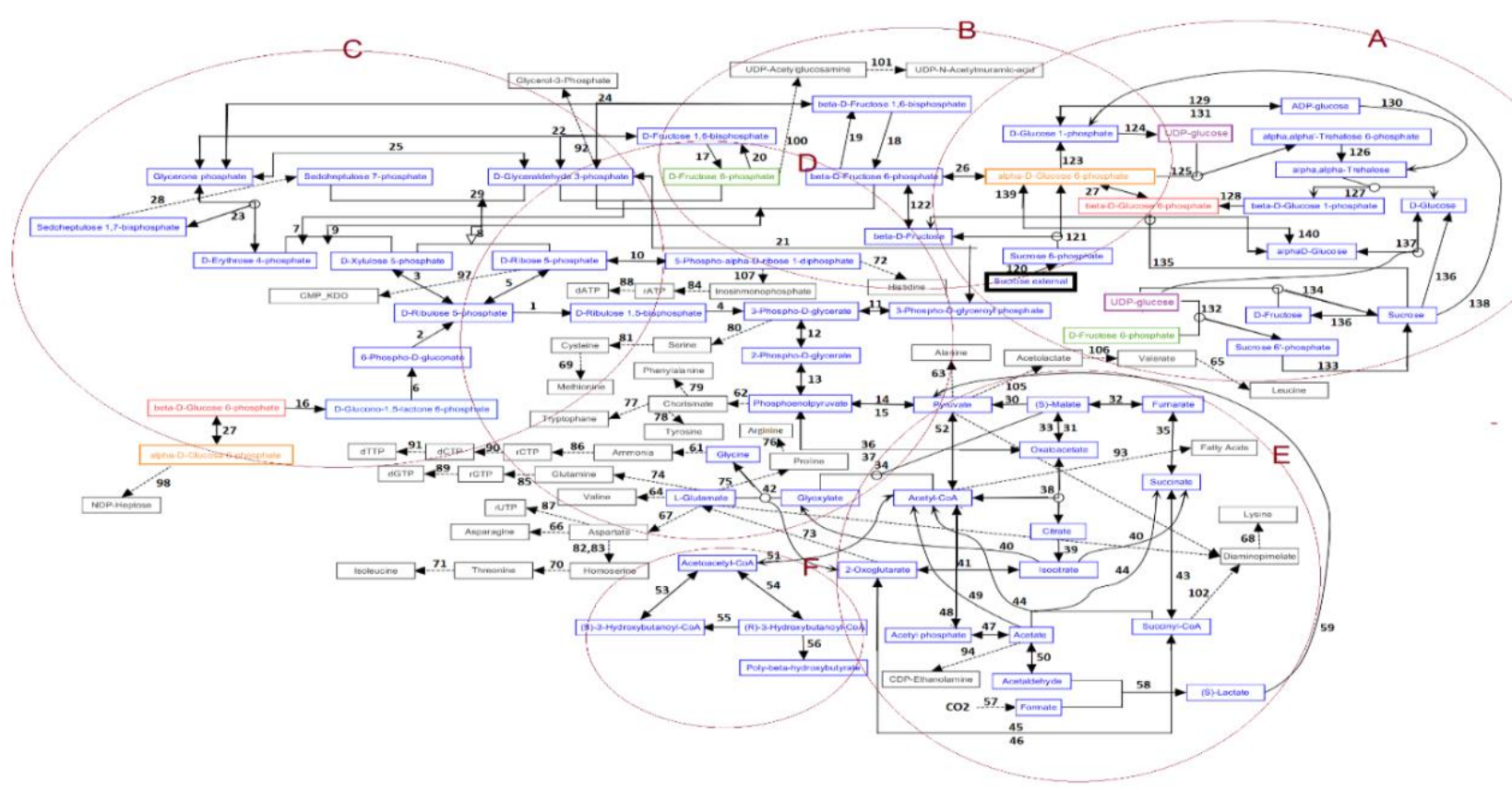

Figure 2. Central carbon flow in R. palustris for growth on sucrose (A: Sucrose pathway, B: Glycolysis, C: Pentose phosphate pathway, D: Calvin cycle, E: TCA cycle, F: PHB synthesis). 


\section{Model parameters and cases}

An experimental work was carried out by Sagir et al. (2017), to produce hydrogen from sucrose and molasses by $R$. palustris in $50 \mathrm{ml}$ small-scale batch photobioreactors. The researchers reported the timedependent profiles of the medium $\mathrm{pH}$, bacterial growth, hydrogen production and observed the soluble endproducts acetic acid, formic acid and lactic acid. This experimental study was used for the input parameters (known fluxes) and formed the basis of comparing the outputs of the model calculation results with the experiment.

The three main input fluxes calculated from the actual values of the bacterial growth medium used in the experimental hydrogen production setup of Sagir et al. (2017) are the glutamate uptake rate, the initial sucrose consumption rate and the photon flux all in units of $\mathrm{mmol} / \mathrm{h}$ per culture liter. The default values of these inputs derived from the experimental data are listed as Case 0 , in Table 2 below, with the remaining cases corresponding to the studies where the effect of changes in input fluxes were analyzed.

Note that in all cases, the medium is nitrogenlimited in order to mimic natural hydrogen production conditions, which is the primary focus of this study. As shall be seen below, this limitation is a central constraint that governs the features of the model solution.

Table 2. List of model cases

\begin{tabular}{ccccc}
\hline Case & $\begin{array}{c}\text { Glutamate } \\
\text { uptake } \\
\text { rate } \\
(\mathbf{m m o l} / \mathrm{h})\end{array}$ & $\begin{array}{c}\text { Initial } \\
\text { sucrose } \\
\text { flux } \\
(\mathbf{m m o l} / \mathrm{h})\end{array}$ & $\begin{array}{c}\text { Photon } \\
\text { flux } \\
(\mathbf{m m o l} / \mathrm{h})\end{array}$ & $\begin{array}{c}\text { Organic } \\
\text { acid uptake } \\
\text { rate } \\
(\mathbf{m m o l} / \mathrm{h})\end{array}$ \\
\hline 0 (Base) & 0.1 & 0.25 & 5 & 0 \\
1 & 0.1 & 0.25 & varied & 0 \\
2 & 0.1 & 0.25 & 5 & varied \\
\hline
\end{tabular}

\section{Comparison of the model with experimental data}

The performance of the model was tested using the aforementioned experimental data (Sagir et al., 2017). For comparison of the model results, the times of maximum bacterial growth rate $\left(24^{\text {th }}\right.$ hour) and maximum hydrogen production rate (48 hour) for 5 $\mathrm{mM}$ sucrose in the experimental study were selected, since FBA is essentially based on the steady-state approximation, as mentioned previously. For the production of organic acids such as acetic acid, lactic acid and formic acid, the lower and upper values of the ranges given in the tables correspond to the organic acid fluxes at 0 and $72^{\text {nd }}$ hours of the experimental data, which is the targeted time period for this model.

Table 3 compares the experimental and computed hydrogen production rates with sucrose concentration and glutamate concentrations of $5 \mathrm{mM}$ and $2 \mathrm{mM}$, respectively. The model results agree well with experimental data. The percent errors between the experimental and model rate results are $11.8 \%$ for production of biomass, $2.9 \%$ for hydrogen production and $4.2 \%$, for the maximum hydrogen production, in which the maximum hydrogen production objective was set. Furthermore, the model correctly predicts organic acid production, and their fluxes are within the given range of experimental results. The sucrose conversion efficiency, obtained from the sucrose uptake flux of the base case of the model, and defined as the rate of hydrogen production $(0.68 \mathrm{mmol} / \mathrm{h})$ divided by theoretical (that is, maximum possible) rate of hydrogen production $(1.2 \mathrm{mmol} / \mathrm{h})$, was compared to the efficiency observed by Sagir et al. (2017). The efficiency calculated from the model was $56 \%$, very close to the experimental efficiency of $53 \%$.

\section{Growth and hydrogen production}

The growth rate (flux 147) was the same $(0.0118 \mathrm{~g}$ dry cell weight/h) for two different objective functions of maximum growth and maximum hydrogen production, presumably due to the nitrogen limitation. It is customary to classify bacterial growth into the lag, exponential and stationary phases. The exponential phase is where maximum biomass production rate is observed, whereas maximum hydrogen is produced in the late-exponential and stationary phases (Waligorska et al., 2009). It may be speculated that in the present model, the nitrogen-limited environment causes a low biomass growth rate, which brings the point of maximum biomass growth rate closer to the point of maximum hydrogen production rate. Therefore, having the same growth rate for two different objective functions is expected in the case of high nitrogen to carbon ratio.

Hydrogen is produced by the enzymes nitrogenase and hydrogenase when excess electrons and ATP are available. The $R$. palustris genome contains genes encoding three separate nitrogenases based on the different metals in their active sites (Mo, V and Fe). The presence of alternative nitrogenase enzymes was supported by the microarray analysis of $R$. palustris

Table 3. Experimental and computed output parameters for the base case

\begin{tabular}{llll}
\hline Control parameters & Units & Experimental result & Model result \\
\hline Biomass production rate & $(\mathrm{gdcw} / \mathrm{h})$ & 0.0104 & 0.0118 \\
Hydrogen production rate $^{\mathrm{a}}$ & $(\mathrm{mmol} / \mathrm{h})$ & 0.70 & 0.68 \\
${\text { Max } \mathrm{H}_{2} \text { production }}^{\mathrm{b}}$ & $(\mathrm{mmol} / \mathrm{h})$ & 0.86 & 0.83 \\
Acetic acid production & $(\mathrm{mmol})$ & $0.004-0.108$ & 0.0128 \\
Lactic acid production $_{\text {Formic acid production }}$ & $(\mathrm{mmol})$ & $0.008-0.09$ & 0.0127 \\
Sucrose conversion efficiency & $(\mathrm{mmol})$ & $0.02-0.12$ & 0.087 \\
\hline
\end{tabular}

a Using biomass growth as the objective function

${ }^{b}$ Using hydrogen production as the objective function 
during nitrogen starvation (McKinlay, 2014), as similar to the present modeling case. All nitrogenase isozymes use the same number of electrons for $\mathrm{H}_{2}$ production. The relevant reactions and the corresponding fluxes are displayed in Table 4.

Table 4. Significant changes between the flux distributions of the maximum growth objective and the maximum $\mathrm{H}_{2}$ production objective

\begin{tabular}{lcc}
\hline Reaction & $\begin{array}{c}\text { Objective: } \\
\text { Maximum Growth } \\
\text { (mmol/h) }\end{array}$ & $\begin{array}{c}\text { Objective: } \\
\text { Maximum } \mathbf{H}_{\mathbf{2}} \\
\text { (mmol/h) }\end{array}$ \\
\hline $\mathrm{H}_{2}$ Production & 0.678 & 0.784 \\
PHB Production & 0.0011 & 0 \\
Acetate Production & 0.00053 & 0 \\
Lactate Production & 0.00053 & 0 \\
Formate Production & 0.0036 & 0 \\
\hline
\end{tabular}

The hydrogen production rate of one of the nitrogenase isoenzymes $(0.047 \mathrm{mmol} / \mathrm{h})$ is lower than the hydrogen production rate of hydrogenase $(0.11$ $\mathrm{mmol} / \mathrm{h}$ ). This agrees with the literature stating that the catalytic rate of nitrogenase is lower than the rate of hydrogenase (Basak et al., 2007).

When the objective function was switched to maximization of hydrogen production, the total hydrogen production increased as expected, compared to the results of the growth objective function. The most noteworthy changes (Table 4) included the complete elimination of PHB and organic acids production. For a real physical case, this would represent the maximum possible diversion of reducing equivalents generated from the substrate to hydrogen production, including the consumption of organic acids produced during growth. The PHB production rate is zero in the case of maximum hydrogen production since $\mathrm{PHB}$ production competes with $\mathrm{H}_{2}$ for reducing equivalents and ATP.

\section{Effect of illumination (photon flux)}

A range of photon fluxes $(0-200 \mathrm{mmol} / \mathrm{h})$ was utilized to observe the effect of photon flux on the specific growth rate, $\mathrm{H}_{2}$ production rate and $\mathrm{PHB}$ production rate. Results are presented in Figure 3. Rates for specific growth and sucrose consumption were constant at each photon flux for both objective functions, due to the nitrogen-limited conditions.

For maximum biomass growth as the objective, the highest $\mathrm{H}_{2}$ production flux was obtained with a photon flux of $10 \mathrm{mmol} / \mathrm{h}$, and $5 \mathrm{mM}$ sucrose and $2 \mathrm{mM}$ glutamate initially. Sasikala et al. (1995) stated that hydrogen production saturated around 5000 lux, corresponding to a photon flux of $13 \mathrm{mmol} / \mathrm{h}$, close to the value found in this work. At higher photon fluxes, $\mathrm{H}_{2}$ production decreases because of the inhibitory effect on $\mathrm{H}_{2}$ production. The highest irradiation of the day $(0.9$ $\mathrm{kW} / \mathrm{m}^{2}$ ), corresponding to a photon flux of $30 \mathrm{mmol} / \mathrm{h}$, was experimentally observed to deteriorate $\mathrm{H}_{2}$ production (Miyake et al., 1999). Model results are consistent with this observation, showing a significant decrease in hydrogen production at photon fluxes of 10-
$30 \mathrm{mmol} / \mathrm{h}$. It is interesting that this inhibition effect is reproduced in the model without an additional, explicit constraint. Presumably, when the photon flux is too high, the model cannot balance the equations within the set of constraints.

PHB production was found to be antagonistic to $\mathrm{H}_{2}$ production as it competes with the latter for reducing equivalents and ATP. According to the flux distribution, when the photon flux increases, more ATP is produced by ATP synthase. However, $\mathrm{H}_{2}$ production decreases after a certain photon flux $(10 \mathrm{mmol} / \mathrm{h})$ because of the increase in PHB production. Nitrogenase cannot utilize the excess ATP converted from high intensity light (McKinlay \& Hardwood, 2010) and therefore ATP is used for other pathways such as organic acid and PHB synthesis, which in turn decreases hydrogen production.

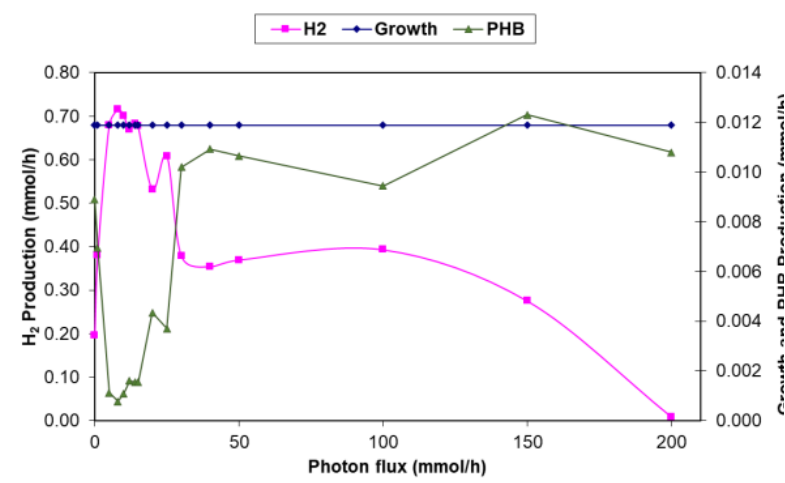

Figure 3. The effect of the value of photon flux on growth, $\mathrm{H}_{2}$ production and PHB production.

Even with zero photon flux, the simulation predicts growth and $\mathrm{H}_{2}$ production. The reason is that bacteria use energy from organic sources in the growth media. Additionally, organic acid production rates are higher initially as seen in Figure 3. It has been established experimentally that PNSB are capable of darkfermentation (Uffen \& Wolfe, 1970; Koku et al., 2002; Oh et al., 2004).

\section{Utilization of organic acids}

The PNSB are known to consume, as well as produce, organic acids during growth. To investigate organic acid consumption behavior of the model, input fluxes were given for the formate, acetate and lactate. Table 5 presents the individual effects of adding organic acids (in addition to sucrose) on $\mathrm{H}_{2}$ production in the case of maximum biomass growth as the objective function. Without organic acids, hydrogen production rate was $0.6783 \mathrm{mmol} / \mathrm{h}$. The production rate was found to increase with increasing initial flux of the organic acids since they could be consumed as supplemental substrates. The rate of hydrogen production was mildly higher for acetic acid compared to lactic acid, and the lowest rate was obtained for formic acid. An experimental hydrogen production study with $R$. palustris, in which both sucrose and several organic acids were utilized could not be found, but the model results are comparable with the experimental results of 
Barbosa et al. (2001) who obtained the highest hydrogen production performance with $R$. palustris on acetate and those of Uyar et al. (2009) who obtained highest hydrogen productivities using acetic and lactic acid as substrates to $R$. capsulatus, another PNSB.

Table 5. Individual effects of organic acids on $\mathrm{H}_{2}$ production

\begin{tabular}{|c|c|c|c|}
\hline & \multicolumn{3}{|c|}{ Hydrogen production rate (mmol/h) } \\
\hline No acid added & & 0.6783 & \\
\hline Initial flux of & Acetate & Lactate & Formate \\
\hline $0.001 \mathrm{mmol} / \mathrm{h}$ & 0.6846 & 0.6826 & 0.6825 \\
\hline $0.004 \mathrm{mmol} / \mathrm{h}$ & 0.6952 & 0.6935 & 0.6851 \\
\hline $0.010 \mathrm{mmol} / \mathrm{h}$ & 0.7150 & 0.7130 & 0.6901 \\
\hline
\end{tabular}

\section{Conclusion}

FBA was used to model the hydrogen production metabolic network of $R$. palustris using 148 reconstructed biochemical reactions and 128 compounds, and flux distributions were obtained based on different cases defined for the model. Model results agreed well with previous experimental data. The hydrogen production rate was estimated as 0.68 $\mathrm{mmol} / \mathrm{h}$ compared to the experimental value of 0.7 $\mathrm{mmol} / \mathrm{h}$. The model predicted a substrate conversion efficiency of $56 \%$, close to the experimental value of $53 \%$. Hydrogen was produced by hydrogenase and nitrogenase, with the production rate of hydrogenase higher than that of nitrogenase. The growth rate was the same for two different objective functions, possibly due to the nitrogen limitations.

The capability of the hydrogen production on sucrose by $R$. palustris was assessed with the results of the metabolic model. Maximum hydrogen production was obtained with $10 \mathrm{mmol} / \mathrm{h}$ photon flux as the input along with $5 \mathrm{mM}$ sucrose and $2 \mathrm{mM}$ glutamate for the case of maximum biomass growth. At higher photon fluxes, $\mathrm{H}_{2}$ production rate decreased and $\mathrm{PHB}$ production was observed to be antagonistic to $\mathrm{H}_{2}$ production for both objective functions. The most and least effective organic acid for $\mathrm{H}_{2}$ production was found as acetic acid and formic acid, respectively. The flux distribution obtained in this work shows that the addition of organic acids to sucrose increases $\mathrm{H}_{2}$ production.

The results can be exploited for further studies to increase yields of hydrogen production. For example, the pathways for organic acid production can be studied to propose sucrose/organic acid combinations resulting in higher yields. Using FBA, intelligent manipulation of the genome to improve the sucrose metabolism of PNSB offers the potential to obtain insight into a low cost hydrogen production system.

\section{Funding Information}

This study was part of project 114M436 supported by the Scientific and Technological Research Council of Turkey (TUBITAK).

\section{Author Contributions}

EMDG: methodology, implementation, analysis, draft version. HK: Conceptualization, supervision and administration, reviewing and editing, final manuscript

\section{Acknowledgements}

We thank the Scientific and Technological Research Council of Turkey (TUBITAK) for the support of this work as part of project $114 \mathrm{M} 436$. We deeply appreciate the insightful scientific feedback and commentary by Prof. Dr. Meral Yücel.

\section{Credit}

This work was based on the M.Sc. thesis studies of the first author, Ezgi Melis Doğan-Güner.

\section{References}

Argun, H., Kargi, F., Kapdan, I. K., \& Oztekin, R. (2008). Biohydrogen production by dark fermentation of wheat powder solution: Effects of $\mathrm{C} / \mathrm{N}$ and $\mathrm{C} / \mathrm{P}$ ratio on hydrogen yield and formation rate. International Journal of Hydrogen Energy, 33(7), 1813-1819. https://doi.org/https://doi.org/10.1016/j.ijhydene.200 8.01 .038

Azbar, N., \& Levin, D. B. (2012). State of the art and progress in production of biohydrogen. Bentham Science Publishers.

Azwar, M. Y., Hussain, M. A., \& Abdul-Wahab, A. K. (2014). Development of biohydrogen production by photobiological, fermentation and electrochemical processes: A review. Renewable and Sustainable Energy Reviews, 31, 158-173. https://doi.org/https://doi.org/10.1016/j.rser.2013.11. $\underline{022}$

Barbosa, M. J., Rocha, J. M. S., Tramper J., \& Wijffels, R. H. (2001). Acetate as a carbon source for hydrogen production by photosynthetic bacteria. J Biotechnol, 85, 25-33.

https://doi.org/10.1016/S0168-1656(00)00368-0

Basak, N., \& Das, D. (2007). The Prospect of Purple Non-Sulfur (PNS) Photosynthetic Bacteria for Hydrogen Production: The Present State of the Art. World Journal of Microbiology and Biotechnology, 23(1), 31-42. https://doi.org/10.1007/s11274-006-9190-9

Caspi, R., Altman, T., Billington, R., Dreher, K., Foerster, H., Fulcher, C. A., Holland, T. A., Keseler, I. M., Kothari, A., Kubo, A., Krummenacker, M., Latendresse, M., Mueller, L. A., Ong, Q., Paley, S., Subhraveti, P., Weaver, D. S., Weerasinghe, D., Zhang, P., \& Karp, P. D. (2016). The MetaCyc database of metabolic pathways and enzymes and the BioCyc collection of pathway/genome databases. Nucleic Acids Res, 44(D1), D471-480. https://doi.org/10.1093/nar/gkv1164

Das, D., \& Veziroğlu, T. N. (2001). Hydrogen production by biological processes: a survey of literature. International Journal of Hydrogen Energy, 26(1), 13-28. https://doi.org/https://doi.org/10.1016/S03603199(00)00058-6 
Edwards, J. S., \& Palsson, B. O. (2000). The Escherichia coli MG1655 in silico metabolic genotype: its definition, characteristics, and capabilities. Proceedings of the National Academy of Sciences of the United States of America, 97(10),

5528-5533.

https://doi.org/10.1073/pnas.97.10.5528

Eroglu, I., Özgür, E., Eroglu, E., Yücel, M., \& Gündüz, U. (2014). Applications of Photofermentative Hydrogen Production. In D. Zannoni \& R. De Philippis (Eds.), Microbial BioEnergy: Hydrogen Production (pp. 237267). Springer Netherlands. https://doi.org/10.1007/978-94-017-8554-9 11

Feist, A. M., \& Palsson, B. O. (2010). The biomass objective function. Current Opinion in Microbiology, 13(3), 344349.

https://doi.org/https://doi.org/10.1016/j.mib.2010.03. 003

Golomysova, A., Gomelsky, M., \& Ivanov, P. S. (2010). Flux balance analysis of photoheterotrophic growth of purple nonsulfur bacteria relevant to biohydrogen production. International Journal of Hydrogen Energy, 35(23), 12751-12760.

https://doi.org/https://doi.org/10.1016/j.ijhydene.201 $\underline{0.08 .133}$

Hallenbeck, P. C., \& Liu, Y. (2016). Recent advances in hydrogen production by photosynthetic bacteria. International Journal of Hydrogen Energy, 41(7), 44464454.

https://doi.org/https://doi.org/10.1016/j.ijhydene.201 $\underline{5.11 .090}$

Imam, S., Yilmaz, S., Sohmen, U., Gorzalski, A. S., Reed, J. L., Noguera, D. R., \& Donohue, T. J. (2011). iRsp1095: A genome-scale reconstruction of the Rhodobacter sphaeroides metabolic network. BMC Systems Biology, 5(1), 116. https://doi.org/10.1186/1752-0509-5-116

Kanehisa, M., Sato, Y., Kawashima, M., Furumichi, M., \& Tanabe, M. (2015). KEGG as a reference resource for gene and protein annotation. Nucleic Acids Research, 44(D1),

D457-D462. https://doi.org/10.1093/nar/gkv1070

Keskin, T., \& Hallenbeck, P. C. (2012). Hydrogen production from sugar industry wastes using single-stage photofermentation. Bioresource Technology, 112, 131136.

https://doi.org/https://doi.org/10.1016/j.biortech.2012 .02 .077

Klamt, S., Schuster, S., \& Gilles, E. D. (2002). Calculability analysis in underdetermined metabolic networks illustrated by a model of the central metabolism in purple nonsulfur bacteria. Biotechnol Bioeng, 77(7), 734751. https://doi.org/10.1002/bit.10153

Koku, H., Eroglu, I., Gunduz, U., Yücel, M., \& Turker, L. (2002). Aspects of the metabolism of hydrogen production by Rhodobacter sphaeroides. International Journal of Hydrogen Energy, 27, 1315-1329. https://doi.org/10.1016/S0360-3199(02)00127-1

Kotay, S., \& Das, D. (2008). Biohydrogen as a renewable energy resource-Prospects and potentials. International Journal of Hydrogen Energy, 33, 258-263. https://doi.org/10.1016/j.ijhydene.2007.07.031

Larimer, F. W., Chain, P., Hauser, L., Lamerdin, J., Malfatti, S., Do, L., Miriam, L. L., Pelletier, D. A., Beatty, J. T., Lang, A. S., Tabita, F. R., Gibson, J. L., Hanson, T. E., Bobst, C., Torres y Torres, J. L., Peres, C., Harrison, F. H., Gibson, J., \& Harwood, C. S. (2004). Complete genome sequence of the metabolically versatile photosynthetic bacterium Rhodopseudomonas palustris. Nature Biotechnology, 22(1), 55-61. https://doi.org/10.1038/nbt923

McEwan, A. G. (1994). Photosynthetic electron transport and anaerobic metabolism in purple non-sulfur phototrophic bacteria. Antonie Van Leeuwenhoek, 66(1-3), 151-164. https://doi.org/10.1007/bf00871637

McKinlay, J. B., \& Harwood, C. S. (2010). Carbon dioxide fixation as a central redox cofactor recycling mechanism in bacteria. Proceedings of the National Academy of Sciences, 107(26), 11669-11675. https://doi.org/10.1073/pnas.1006175107

McKinlay, J. B. (2014). Systems Biology of Photobiological Hydrogen Production by Purple Non-sulfur Bacteria. In D. Zannoni \& R. De Philippis (Eds.), Microbial BioEnergy: Hydrogen Production (pp. 155-176). https://doi.org/10.1007/978-94-017-8554-9 7

Miyake, J., Wakayama, T., Schnackenberg, J., Arai, T., \& Asada, Y. (1999). Simulation of the daily sunlight illumination pattern for bacterial photo-hydrogen production. Journal of Bioscience and Bioengineering, 88(6), 659663. https://doi.org/https://doi.org/10.1016/S13891723(00)87096-6

Navid, A., Jiao, Y., Wong, S. E., \& Pett-Ridge, J. (2019). Systemlevel analysis of metabolic trade-offs during anaerobic photoheterotrophic growth in Rhodopseudomonas palustris. BMC bioinformatics, 20(1), 1-16. https://doi.org/10.1186/s12859-019-2844-z

Oh, Y. K., Raj, S. M., Jung-Gyoo, Y., \& Park, S. (2011). Current status of the metabolic engineering of microorganisms for biohydrogen production. Bioresource Technology, 102(18), 8357-8367. https://doi.org/https://doi.org/10.1016/j.biortech.2011 .04 .054

Oh, Y. K., Seol, E. H., Lee, E. Y., \& Park, S. (2002). Fermentative hydrogen production by a new chemoheterotrophic bacterium Rhodopseudomonas palustris P4. International Journal of Hydrogen Energy, 27(11-12), 1373-1379.

Ozturk, Y., Yücel, M., Daldal, F., Mandacı, S., Gündüz, U., Türker, L., \& Eroğlu, ì. (2006). Hydrogen production by using Rhodobacter capsulatus mutants with genetically modified electron transfer chains. International Journal of Hydrogen Energy, 31(11), 1545-1552. https://doi.org/https://doi.org/10.1016/j.ijhydene.200 $\underline{6.06 .042}$

Sagir, E., Ozgur, E., Gunduz, U., Eroglu, I., \& Yucel, M. (2017). Single-stage photofermentative biohydrogen production from sugar beet molasses by different purple non-sulfur bacteria. Bioprocess Biosyst Eng, 40(11), 1589-1601. https://doi.org/10.1007/s00449-017-1815-x

Sasikala, C. H., Ramana, C. H. V., \& Rao, P. R. (1995). Regulation of simultaneous hydrogen photoproduction duringgrowth by $\mathrm{pH}$ and glutamate in Rhodobacter sphaeroides O.U. 001. International Journal of Hydrogen Energy, 20(2), 123-126. https://doi.org/https://doi.org/10.1016/03603199(94)E0009-N

Schomburg, I., Chang, A., Placzek, S., Söhngen, C., Rother, M., Lang, M., Munaretto, C., Ulas, S., Stelzer, M., Grote, A., Scheer, M., \& Schomburg, D. (2013). BRENDA in 2013: integrated reactions, kinetic data, enzyme function data, improved disease classification: new options and contents in BRENDA. Nucleic acids research, 41(Database issue), D764-D772. 
https://doi.org/10.1093/nar/gks1049

Sparling, R., Carere, C., Rydzak, T., Schellenberg, J., \& Levin, D. B. (2012). Thermodynamic and biochemical aspect of hydrogen production by dark fermentation. In N. Azbar \& D. B. Levin (Eds.), State of the Art and Progress in Production of Biohydrogen (pp. 160-188). https://doi.org/10.2174/978160805224011201010160

Stephanopoulos, G. N., Aristidou, A. A., \& Nielsen, J. (1998). CHAPTER 8 - Metabolic Flux Analysis. 309-351.

https://doi.org/https://doi.org/10.1016/B978012666260-3/50009-1

Uffen R. L., \& Wolfe R. S. (1970). Anaerobic growth of purple nonsulfur bacteria under dark conditions. Journal of Bacteriology, 104(1), 462-472.

https://doi.org/10.1128/jb.104.1.462-472.1970

Uyar, B., Eroglu, I., Yücel, M., \& Gündüz, U. (2009). Photofermentative hydrogen production from volatile fatty acids present in dark fermentation effluents. International Journal of Hydrogen Energy, 34(10), 45174523.

https://doi.org/https://doi.org/10.1016/j.ijhydene.200 8.07.057

Varma, A., \& Palsson, B. O. (1993). Metabolic Capabilities of Escherichia coli II. Optimal Growth Patterns. Journal of Theoretical Biology, 165(4), 503-522. https://doi.org/https://doi.org/10.1006/jtbi.1993.1203
Varma, A., \& Palsson, B. O. (1994). Metabolic Flux Balancing: Basic Concepts, Scientific and Practical Use. Bio/Technology, 12(10), 994-998. https://doi.org/10.1038/nbt1094-994

Venkataraman, P. (2009). Applied Optimization with MATLAB Programming. Wiley Publishing.

Vignais, P. M., Colbeau, A., Willison, J. C., \& Jouanneau, Y. (1985). Hydrogenase, Nitrogenase, and Hydrogen Metabolism in the Photosynthetic Bacteria. Advances in Microbial Physiology, 26, 155-234. https://doi.org/https://doi.org/10.1016/S00652911(08)60397-5

Waligórska, M., Seifert, K., Górecki, K., Moritz, M., \& Laniecki, M. (2009). Kinetic model of hydrogen generation by Rhodobacter sphaeroides in the presence of $\mathrm{NH}$ ions. $J$ Appl Microbiol, 107(4), 1308-1318. https://doi.org/10.1111/j.1365-2672.2009.04314.x

Zhang, D., Xiao, N., Mahbubani, K. T., del Rio-Chanona, E. A., Slater, N. K. H., \& Vassiliadis, V. S. (2015). Bioprocess modelling of biohydrogen production by Rhodopseudomonas palustris: Model development and effects of operating conditions on hydrogen yield and glycerol conversion efficiency. Chemical Engineering Science, 130, 68-78. https://doi.org/https://doi.org/10.1016/j.ces.2015.02.0 $\underline{45}$ 